\title{
Which doctors have been shortlisted for the BMJ Awards India 2014?
}

\author{
The "Oscars of medicine" are coming to New Delhi. We have shortlisted the nominations and \\ appointed the judges. We'll be announcing the winners at our inaugural awards ceremony on 20 \\ September 2014. Richard Hurley reports
}

\section{Richard Hurley deputy magazine editor, The BMJ}

We received more than 500 high quality nominations for the first BMJ Awards India, showing medical excellence in diverse work throughout India. ${ }^{12}$ The BMJ team in India had the unenviable task of whittling these down to 30 nominations across the 10 categories.

Doctors representing these 30 will present their work to a panel of 10 judges, chosen for their record in clinical excellence, research, and policy, on Friday 19 September (box).

The winners will be announced at a lavish ceremony in the opulent Crystal Ballroom at the five star J W Marriott Aerocity hotel in New Delhi the following evening. Proceedings will be overseen by celebrity Bollywood hosts, Vir Das and Shibani Dandekar.

Healthcare dignitaries will present the winners with a trophy and certificate, before an audience of 500 of India's most senior healthcare professionals, industry executives, government officials, academics, and researchers, including all the shortlisted individuals and teams.

BMJ's India editor, Anita Jain, said, "We have received a diverse and exciting mix of entries from all parts of India. Nominations range from high end technological innovation and research, exceptional surgical expertise and clinical acumen, to examples of unwavering perseverance in delivering primary care services in remote areas. These demonstrate true potential to influence change and improve health outcomes. I have been inspired by what India has to offer to global health at large. Choosing the winners among these excellent nominations is not going to be an easy task."

Commiserations to those excellent nominations that were not quite excellent enough, and the best of luck to all those doctors and teams shortlisted, who must now prove to the judges that they deserve to come top in the first BMJ Awards India.

\section{Excellence in preventive health}

For demonstrable success in health promotion or secondary prevention:
- Billion Hearts Beating Foundation, Apollo Hospitals Group (Ravinder Uberoi)

- kNOw diabetes project (primary prevention of diabetes and other lifestyle diseases through targeted approach), Kerala (G Vijayakumar)

- Decentralising drug resistant tuberculosis centre services by offering "virtual consultancy"-Kozhikode model, Kerala (Sunny George)

- Cardiovascular disease prevention and management programme - a rural model, Karnataka (Gift Norman)

\section{Research paper of the year}

For original Indian research that has the potential to improve health and healthcare:

- Effect of early skin-to-skin contact after following normal delivery on incidence of hypothermia in neonates more than $1800 \mathrm{~g}$ : randomized control trial. J Perinatol 2014;34:364-8 (Somashekhar Nimbalkar, Karamsad, Gujarat)

- Undernutrition and the incidence of tuberculosis in India: national and subnational estimates of the population attributable fraction related to undernutrition. Nat Med J India 2014;27:e4-9 (Anurag Bhargava, Himalayan Institute of Medical Sciences, Jolly Grant, Uttarakhand)

- Associations between active travel to work and overweight, hypertension, and diabetes in India: a cross-sectional study. PLoS Med 2013;10:e1001459 (Vikram Patel, South Asia Network for Chronic Diseases, Public Health Foundation of India, and the London School of Hygiene and Tropical Medicine) 


\section{Primary healthcare in challenging circumstances}

For saving lives or improving health indicators of a population in difficult conditions:

- Jawadhi Hills Health and Development Project, Tamil

Nadu (Anuradha Rose)

- Morbidity control of lymphatic filariasis using integrative treatment, Kerala (Saravu R Narahari)

\section{Health advocacy}

For work towards bringing a change in policy that has the potential to influence health:

- Pallium India (M R Rajagopal, Kerala)

- Voice of Tobacco Victims (Pankaj Chaturvedi, Mumbai)

- Deceased Donor Multiorgan Transplantation Programme, Kerala (Ramdas Pisharody)

\section{Junior doctor of the year}

For an unsung junior hero of healthcare, balancing day to day work with training:

- Mohan Patel, B J Medical College, Ahmedabad

- Pathik Patel, Karnavati School of Dentistry, Gandhinagar

\section{Surgical team of the year}

For a team whose project has measurably improved surgical care:

- Transplant Surgery Unit at Apollo Hospitals, New Delhi (Karan Thakur)

- Centre for Liver and Biliary Sciences, Indraprastha Apollo Hospital, New Delhi (Subash Gupta)

- Robotic spine surgery team, Apollo Hospitals, New Delhi (Ravinder Uberoi)

\section{Medical team of the year}

For a project that has improved medical care for either patients or their carers or that has had a population-wide effect:

- Clinical haematology service, City Hospital, New Delhi (Anupama Jaggia)

- Antibiotic review programme, Fortis Hospital, Mumbai (Supriya Amey)

- Diabetes team, Max Healthcare, New Delhi (Sujeet Jha)

\section{Innovation in healthcare technology}

For innovation that has improved the outcomes and experience of patients:
- Novel rapid test kits for visceral leishmaniasis, All India Institute of Medical Sciences, New Delhi (Sarman Singh)

- A novel intraosseous device for emergency vascular access, Stanford-India Biodesign Center, All India Institute of Medical Sciences, New Delhi (Sandeep Singh)

- Bhattacharjee pupil expansion ring, Kolkata (Suven Bhattacharjee)

\section{Excellence in medical education}

For outstanding innovation in educating Indian healthcare professionals and improving performance:

- Improving research aptitude of trainees in a neurology programme, Postgraduate Institute of Medical Education and Research, Chandigarh (Dheeraj Khurana)

- Certificate course in evidence based diabetes management, Public Health Foundation of India, New Delhi (Sandeep Bhalla)

- Live telecast of teaching sessions, Jawaharlal Institute of Postgraduate Medical Education and Research, Pondicherry (Ravi Kumar Chittoria)

\section{Quality improvement in healthcare}

For a specific initiative that has significantly improved healthcare quality:

- Reducing caesarean section rates in a non-profit hospital in urban India, Sitaram Bhartia Institute of Science and Research, New Delhi (Rinku Sengupta Dhar)

- Reducing readmission rates in the hospital through integrated care cycle, Apollo Gleneagles Hospitals, Kolkata (Sujoy Kar)

- Paediatric cardiac unit, Amrita Institute of Medical Sciences, Kochi (Krishna Kumar)

- Accreditation programme, National Neonatology Forum of India, New Delhi (Vikram Datta)

Competing interests: I have read and understood BMJ policy on declaration of interests and have no relevant interests to declare. See http://awards.bmjindia.com for more details.

Follow @BMJIndia on Twitter for all the latest news and use the hashtag \#BMJAwardsIndia

Provenance and peer review: Commissioned; not externally peer reviewed.

1 Hurley R. The "Oscars of medicine" are coming to New Delhi: who will you nominate as a hero of Indian healthcare? BMJ 2014;349:g4540.

2 D'Silva J. Judging the best of Indian healthcare. BMJ 2014;349:g5454.

Cite this as: BMJ 2014;349:95662

๑ BMJ Publishing Group Ltd 2014 


\section{Confirmed judges}

- Anoop Mishra, director and head, Department of Diabetes and Metabolic Diseases, Fortis Hospitals

- Samiran Nundy, emeritus consultant, Surgical Gastroenterology and Liver Transplantation, Sir Ganga Ram Hospital, Delhi

- Nata Menabde, WHO representative to India

- Ashok Seth, chairman of Cardiology Council, Fortis Group of Hospitals

- Payal Bansal, associate professor and head, Department of Medical Education and Technology and convener, $\mathrm{MCI}$ Regional Centre for Faculty Development, Maharashtra University of Health Sciences, Regional Centre, Pune

- T V Devarajan, consultant, Apollo Hospitals, Chennai

- Velu Nair, dean, Armed Forces Medical College, Pune

- Himanshu Pandya, professor of medicine and convenor, MCI Nodal Centre for Faculty Development, Pramukhswami Medical College, Karamsad, Gujarat

- Prabhakaran Dorairaj, vice-president, Public Health Foundation of India, and director, Centre of Excellence in Cardiometabolic Risk Reduction in South Asia

- Balraj Mittal, professor of medical genetics and honorary chief librarian, Sanjay Gandhi Postgraduate Institute of Medical Sciences, Lucknow 